NBSIR 75-964

\title{
An Evaluation and Assessment of Existing Data and Procedures for the Measurement of Noise from Truck Transport Refrigeration Units
}

Applied Acoustics Section Institute for Basic Standards National Bureau of Standards Washington, D. C. 20234

December 1975

Final Report

Prepared for

Office of Noise Abatement and Control U. S. Environmental Protection Agency Washington, D. C. 20460 



\section{AN EVALUATION AND ASSESSMENT OF EXISTING DATA AND PROCEDURES FOR THE MEASUREMENT OF NOISE FROM} TRUCK TRANSPORT REFRIGERATION UNITS

Applied Acoustics Section Institute for Basic Standards National Bureau of Standards

Washington, D. C. 20234

December 1975

Final Report

\section{Prepared for}

Office of Noise Abatement and Control U. S. Environmental Protection Agency Washington, D. C. 20460

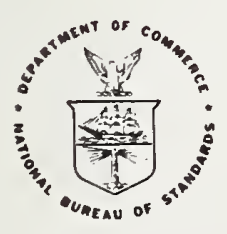

U.S. DEPARTMENT OF COMMERCE, Rogers C.B. Morton, Socrotary James A. Baker, III, Under Secretery Dr. Betsy Ancker-Johnson, Assistant Secretary for Science and Techmology 

Executive Summary . . . . . . . . . . . . . . . . . . . i i

Acknowledgements . . . . . . . . . . . . . . . . . . . . . iv

1. Introduction and Scope . . . . . . . . . . . . . . . . . 1

2. Description and Design Characteristics of Truck Transport

Refrigeration Units . . . . . . . . . . . . . . . . 2

2.1. Definition .. . . . . . . . . . . . . . . 2

2.2. Design Characteristics/Normal Operation . . . . . . . 2

3. Effects of Noise and Parties Affected . . . . . . . . . . . . . 4

4. Existing Measurement Procedures and Data Base. . . . . . . . . . 4

5. Overview of Truck Transport Refrigeration Unit Noise

Measurement Difficulties . . . . . . . . . . . . . . 5

5.1. Characteristics of the Radiated Sound . . . . . . . . 5

5.2. Choice of Appropriate Metric . . . . . . . . . . 8

5.2.1. Relationship of Appropriate Metric to the Subjective Data Base.................. . 8

5.2.2. Quantity to be Measured . . . . . . . . . 8

5.3. Noise Measurement Considerations . . . . . . . . . . 10

5.3.1. Facilities and Measurement Procedures . . . . . 10

5.3.2. Special Site and Environmental Considerations . . . 12

5.3.3. Provision of a Physical Data Base . . . . . . . 13

5.4. Summary . . . . . . . . . . . . . . . . . 14

6. References . . . . . . . . . . . . . . . . . 14 
EPA is charged with taking strong, comprehensive action to protect public health and welfare from increasing nolse. Accordingly, the Agency initially identified medium and heavy trucks and portable air compressors as major noise sources and promulgated noise emission regulations covering these products. Additional products have recently been identified as major noise sources, including truck transport refrigeration units (truck mounted auxilliary equipment). Although EPA recognizes that the noise impact from truck transport refrigeration units alone is not as great as some other noise sources, control of this source is required to avoid reducing the effectiveness of actions already taken to control noise emissions from medium and heavy trucks.

This report reviews existing noise measurement procedures with regard to their usefulness in the regulation of truck transport refrigeration noise as well as the availability, extent and applicability of existing data. On the basis of this review, the following probable or potential measurement difficulties have been identified that could hinder the promulgation and/or enforcement of future EPA regulations to control the noise emission from truck transport refrigeration units.

NEED TO ESTABLISH A SUBJECTIVE DATA BASE. There exists a need to conduct a psychoacoustic study to determine what characteristics of the truck transport refrigeration unit noise spectrum annoy people. A more complex measure than the A-weighted sound level may be necessary. This subjective data base is necessary before a suitable physical measure can be selected which correlates with human response and before an appropriate measurement procedure can be established.

NEED TO DEFINE APPROPRIATE METRIC. There exists a need to define the appropriate acoustic quantity(ies) to be measured. Since the frequency spectrum typical of a diesel-powered truck transport refrigeration unit is dominated by the low frequency (less than 100 $\mathrm{Hz}$ ) fundamental associated with the engine firing frequency, the use of the A-weighted sound level as a metric must seriously be questioned. The use of a simple metric such as the A-weighted sound level may result in a situation in which adequate incentives for reduction of low frequency components of the noise are not provided.

NEED TO DEVELOP AN APPROPRIATE MEASUREMENT PROCEDURE. No one standardized procedure presently exists which can be directly utilized for measurement of truck transport refrigeration unit noise. Adequate data do not exist to allow one to decide whether the noise emission from these units should be regulated on the basis of the sound pressure level at a particular location, or set of locations, or on the sound power output of the device. It is not possible to select either the appropriate acoustic quantity to be measured or the appropriate measurement procedure and test environment without adequate subjective and physical data bases. 
- NEED TO ACCOUNT FOR ENVIRONMENTAL/SITE EFFECTS. If an outdoor test environment (e.g., free field over a reflecting plane) is deemed appropriate, there is a need for the varfous environmental and test site effects on noise generation, radiation and/or propagation to be systematically investigated and correction factors developed so that measurements made under any conditions may be corrected to a single standard set of conditions. If correction factors are not feasible then there is a need for a site calibration procedure or definition of limiting test conditions. If an indoor test environment (e.g., indoor semi-anechoic or reverberant) is chosen, then it is necessary to establish the relationship between "real world" noise radiation characteristics such as directionality or possible secondary source radiation due to vibration of the truck body and the characteristics observed in the indoor environment.

- NEED TO DEFINE PROCEDURE FOR OBTAINING MAXIMUM UNIT LOADING. The maximum cooling capacity, and therefore maximum unit loading, for truck transport refrigeration units is typically specified for an outside air temperature of $100^{\circ} \mathrm{F}\left(37.8^{\circ} \mathrm{C}\right)$. If an outdoor test procedure is eventually selected some alternative environmental loading procedure will have to be specified. If, an indoor test utilizing a well-characterized acoustic environment is selected, the chamber will have to be capable of supplying the required thermal load to the refrigeration unit and be capable of handling the exhaust effluent from the engine.

NEED TO ESTABLISH A PHYSICAL DATA BASE. Almost no objective data exist in the public domain on the noise levels associated with truck transport refrigeration unit operation.

In summary, existing data -- both objective and subjective -- are not sufficient to allow EPA to (1) select a suitable physical metric that correlates with human response, (2) establish an appropriate measurement procedure, and (3) perform a comprehensive analysis of the economic costs and technical feasibility associated with a given regulation. Thus, it appears that EPA should generate an extensive physical and psychoacoustic data base and investigate alternative measurement procedures prior to formulation of the Notice of Proposed Rule Making. 
The National Bureau of Standards (NBS) gratefully acknowledges the assistance of the individuals and organizations whose contributions have helped make it possible to produce this report.

Of great assistance to the NBS was the Air Conditioning and Refrigeration Institute's (ARI) Sub-Committee on Transport Refrigeration Sound which provided technical expertise and back-up data -- both acoustic and product. The sub-committee members included: Mr. Charles E. Ebbing and Mr. L. Thomas Lane (Carrier Corporation), Mr. Donald D. King (Thermo-King Corporation), Mr. Daniel L. Saxton (Therm-Air Mfg. Co., Inc.), Mr. Robert G. Harold and Mr. Richard Vaughn (The Trane Company) and Mr. Robert Stabley (York). We would also like to thank Mr. Robert J. Evans (ARI) who assisted in assembling this sub-committee.

We thank all of these people for their cooperation and contributions. 
An Evaluation and Assessment of Existing Data and Procedures for the Measurement of Noise from Truck Transport Refrigeration Units

This report reviews existing noise measurement procedures with regard to their usefulness in the regulation of truck transport refrigeration noise as well as the availability, extent and applicability of existing data. On the basis of this review, probable or potential measurement difficulties are identified that could hinder the promulgation and/or enforcement of future EPA regulations to control the noise emission from truck transport refrigeration units.

Key Words: Acoustics (sound); measurement methodology; noise emission standard; noise measurement; refrigeration; truck transport refrigeration unit.

\section{Introduction and Scope}

EPA has identified// truck transport refrigeration units as a major noise source. Even though EPA recognizes that the noise impact from such special purpose equipment alone is not as great as some other noise sources, control of this source is required to avoid reducing the effectiveness of actions already taken to control noise emissions from medium and heavy trucks.

The National Bureau of Standards (NBS), under the sponsorship of the Office of Noise Abatement and Control (ONAC), U. S. Environmental Protection Agency (EPA), has attempted to identify probable or potential measurement difficulties that could hinder the promulgation and/or enforcement of future noise regulations to control the noise emissions from truck transport refrigeration units. A search of the open literature in conjunction with numerous industrial and private sector contacts established the basis for discussion of:

1. The basic characteristics of truck transport refrigeration systems and their design.

2. The effects of noise emission from such units and the parties affected.

3. The normal or typical mode of operation characteristic of various types of refrigeration systems.

4. The usefulness of existing measurement procedures for use in regulation of the noise from truck transport refrigeration units considering the viewpoint of EPA, manufacturers and enforcement personnel.

5. The availability, extent and applicability of existing data that could be utilized by EPA in their efforts to promulgate noise emission regulations for truck transport refrigeration units.

$1 /$ See Federal Register, Vol. 40, No. 103 - Wednesday, May 28, 1975. 
This report is limited to those factors related to the measurement of truck transport refrigeration unit noise. EPA/ONAC will independently investigate the technical feasibility and economic implications of truck transport refrigeration unit noise regulation.

\section{Description and Design Characteristics of Truck Transport Refrigeration Units}

\subsection{Definition}

A working definition for truck auxiliary eqyjpment was established at the Williamsburg Conference on Noise Research[1] the Vehicle Research Institute, Society of Automotive Engineers (SAE) -"Auxiliary (ancillary) equipment shall consist of any device capable of generating noise which is mounted on (as opposed to readily detachable from) a motor truck, trailer, or truck-trailer combination and which is utilized to perform some task, subsidiary to normal truck propulsion functions." The important concept is the fact that only the noise generated by the truck transport refrigeration unit itself is of interest; truck passby noise is already covered under previous EPA actions.

\subsection{Design Characteristics/Normal Operation}

Truck transport refrigeration units provide the cooling or heating necessary to maintain various types of perishable (temperature dependent) commodities. The majority of these units are front mounted on trailers or containers; however, under-mounted, side-mounted and roof-mounted configurations are also available.

Most refrigeration units have automatic thermostatic temperature control which maintains a pre-selected temperature through cooling or heating as necessary. The units contain both an evaporator and a condenser section. The evaporator section, which generally extends into the trailer or container, typically consists of an evaporator coil, fan, heat exchanger and expansion valve while the condenser section typically contains the engine, compressor, condenser coil, fan, radiator, generator or electric standby motor and unit controls. The engine, compressor and standby motor, when used, are installed on a vibration isolated base. This resilient-mounted system serves to reduce noise caused by the refrigeration unit's engine vibration.

In general, these units have a maximum of two possible operational modes -- high speed operation (e.g., $2200 \mathrm{rpm}$ ) and low speed operation (e.g., $1400 \mathrm{rpm}$ ) -- for either heating or cooling. Single speed models also exist. The net cooling capacity (air to coil) and maximum engine speed for these units is typically specified for an ambient air temperature of $100^{\circ} \mathrm{F}\left(37.8^{\circ} \mathrm{C}\right)$.

Truck transport refrigeration systems are either self-contained

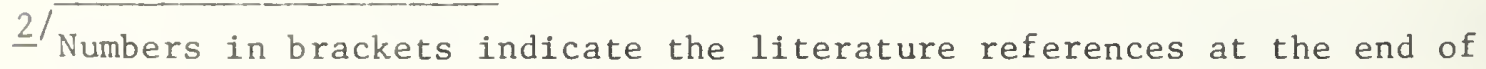
this report. 
(i.e., run off their own power-plant) or depend upon the vehicle engine for operation.

Self-contained units normally employ one of the following engine/compressor configurations

- Diesel engine driven compressor unit.

- Diesel engine driven compressor unit with standby electric motor.

- Gasoline or propane engine driven compressor unit.

- Gasoline or propane engine driven compressor unit with standby electric motor.

- All electric-driven compressor unit.

Most of the refrigeration units that depend on the vehicle power-plant are typically restricted to single-chassis vehicles rather than truck-trailer combination vehicles. These type units can be categorized as follows:

- Truck engine (gasoline or diesel) driven compressor unit.

- Truck engine (gasoline or diesel) driven compressor unit with electric standby motor.

- Hydraulic driven compressor unit from truck engine.

- Power take off driven compressor from truck transmission.

All units tend to be quietest when running in the electric-powered mode.

The engine exhaust for self-contained units is directed from the engine manifold, through a muffler, which is generally located within the refrigeration unit housing, and out the top or side of the unit depending on the particular mounting configuration. An air intake is usually located on the side of the condenser section.

The maximum brake horsepower for truck transport refrigeration units ranges from 8 to $32 \mathrm{hp}$. The diesel engine is capable of generating the maximum horsepower, while the other engines generally fall in the range of 8-15 hp.

Since refrigeration units are designed for mounting on various types of trucks, a convenient categorization is according to intended use:

- Single-chassis truck units

- Trailer units

- Container units 
Single-chassis (or "straight") truck mounted units are utilized on light, medium and heavy van type vehicles typically involved in short haul operations. For long haul applications, units are typically mounted in the trailer of a truck-trailer combination vehicle. Containers refer to a special class of storage container which may be transported by means of a flat-bed truck, railroad car or by ship. Many of these identical units can also be utilized on refrigerated railway cars and on prefabricated warehouses.

\section{Effects of Noise and Parties Affected}

It is important to identify the parties affected by truck transport refrigeration urit noise and the nature of the effects. In general, complaints have come from areas where commodity distribution or storage facilities, such as warehouses or dairies, are located in close proximity to residential areas. At such facilities, large numbers of trucks and/or trailers equipped with refrigerator units are required to operate in order to keep perishable commodities from spoiling until they can be unloaded from their storage containers or for truck pre-cooling prior to loading. Although hearing loss is not a potential problem for persons living near such facilities, task interference and/or annoyance can result from the noise from truck transport refrigeration unit operation. These units are considered especially annoying to the neighboring residents during the late evening due to otherwise low ambient conditions.

A critical deficiency at the present time, is that the subjective data do not exist to determine conclusively if the complaints are primarily due to the characteristic low frequency spectral peak (associated with the engine firing frequency), to the change in noise level as the unit is thermostatically switched from low speed to high speed operation and vice-versa, or to some other complex spectral characteristic.

Without such information it is not possible to select the appropriate acoustic quantity to be neasured or an appropriate measurement procedure, since the objective of the measurement data is to permit a reliable prediction of acceptable noise emission characteristics.

\section{Existing Measurement Procedures and Data Base}

There are no standardized measurement procedures directly applicable to the measurement of the noise generated by truck transport refrigeration uni ss anu, as a consequence, there is practically a non-existent data base available in the public domain on the noise levels associated with these units. This is due, in part, to the fact that in the past the noise levels of the auxilliary equipment tended to be lower than the noise level

$\underline{3}$ To a person located in a house with the windows closed, the automatic change from low speed operation to high speed operation may be percej.ved as simply an off-on operation of the unit. 
of the vehicle on which they were mounted and little effort has been made to isolate auxilliary equipment as a potential major noise source and to determine the environmental impact assoclated with the operation of the auxilliary equipment as a separate source.

Discussions with manufacturers indicates that some proprietory data do exist; however, these data are not sufficiently extensive to provide EPA with even a fraction of the information needed for a comprehensive analysis of the economic costs and technical feasibility associated with a given regulation. Furthermore, it is evident that there are essentially no data available upon which to base the establishment of an appropriate measurement procedure for truck transport refrigeration units.

Thus, it appears that EPA should investigate alternative measurement procedures and should generate an extensive physical data base prior to formulation of the Notice of Proposed Rule Making.

\section{Overview of Truck Transport Refrigeration Unit Noise Measurement Difficulties}

\subsection{Characteristics of the Radiated Sound}

There is little question that subjective response to noise is due to some measurable characteristics of the radiated sound. While there is little reliable technical data at the present time, it is prudent to consider the characteristics of the sound which are important both to the subjective response (perhaps resulting in task interference or annoyance) and to the related measurement difficulties.

There are two principal characteristics which are important

--- the time variability of the sound, and

--- the frequency spectrum.

Refrigeration units typically cycle from high to low speed operation in response to varying thermal demands. This cyclic variation in engine speed results in a corresponding cyclic variation in the sound. While the details of the changes in sound levels are subject to unit-to-unit variability and to the metric selected, at a 50 foot $(15.2 \mathrm{~m})$ distance from a typical truck mounted refrigeration unit, the A-weighted sound levels have been shown to vary from $65.5 \mathrm{~dB}$ to $72 \mathrm{~dB}--$ a difference in level of $6.5 \mathrm{~dB}$. Considering the "Iinear" levels, the difference in levels amounts to $8.5 \mathrm{~dB}$. These differences in level are substantial enough that the subjective loudness differential may be nearly a factor of two to one.

Because of the wide range of this time variation in sound level, and because of the cyclic nature of the variations, it is probable that subjective annoyance to the sound may be higher than if the levels were constant. In effect, the time variation draws listeners attention to the noise source at each transition between operating conditions. 
An adequate psychoacoustic data base for the prediction of annoyance from a sound source with this type of time variability does not exist, and should be obtained prior to selection of the appropriate metric. These psychoacoustic considerations should dictate whether or not special consideration ought to be made of the magnitude and temporal duration of the cyclic variations in sound emissions.

The frequency spectrum of the sound emitted by truck mounted diesel engine powered refrigeration units appear (on the basis of the limited data base presently available) to be characterized by strong discrete frequency or pure tone components at the fundamental firing frequency of the diesel engine as shown in Figure 1.

This line component may be as much as $20 \mathrm{~dB}$ higher than any other component in the spectrum, which gives rise to severe measurement problems due to the possibility of interference effects in the measurement of sound pressures at discrete locations in a free field over a reflecting plane measurement environment, or due to the requirement for extremely large facilities and stringent performance criteria for the measurement of sound power using reverberation rooms.

Furthermore, the frequency of the line component is correlated with operating speed, and when operating speed is lowered for the low load condition, the frequency is reduced and the detailed nature of the interference effects change.

In addition to these complications, if the A-weighting network is employed for measurement of the sound pressure, the low frequency roll-off characteristic of this welghting curve is such that the resultant sound pressure levels are not principally determined by the large amplitude discrete frequency components. Thus, even if the spectrum is radically changed by the incorporation of sufficient muffling capacity to substantially reduce the strength of the line component, the A-weighted sound pressure levels may not be changed.

The simple use of the A-weighting characteristic may not provide much incentive on the part of industry for the reduction of the low frequency line component through better muffling of engine exhaust.

Psychoacoustic studies to determine whether the presence of such a prominent low frequency tone may lead to a high degree of annoyance, and for which specific pure-tone correction procedures ought to be employed as part of the appropriate metric, are essential elements prior to selection of the metric to be employed by EPA in its regulatory actions. Further subjective response considerations must account for the greater annoyance which is probable when these units are operated during evening hours, although these operational considerations do not present difficult physical measurement problems. 


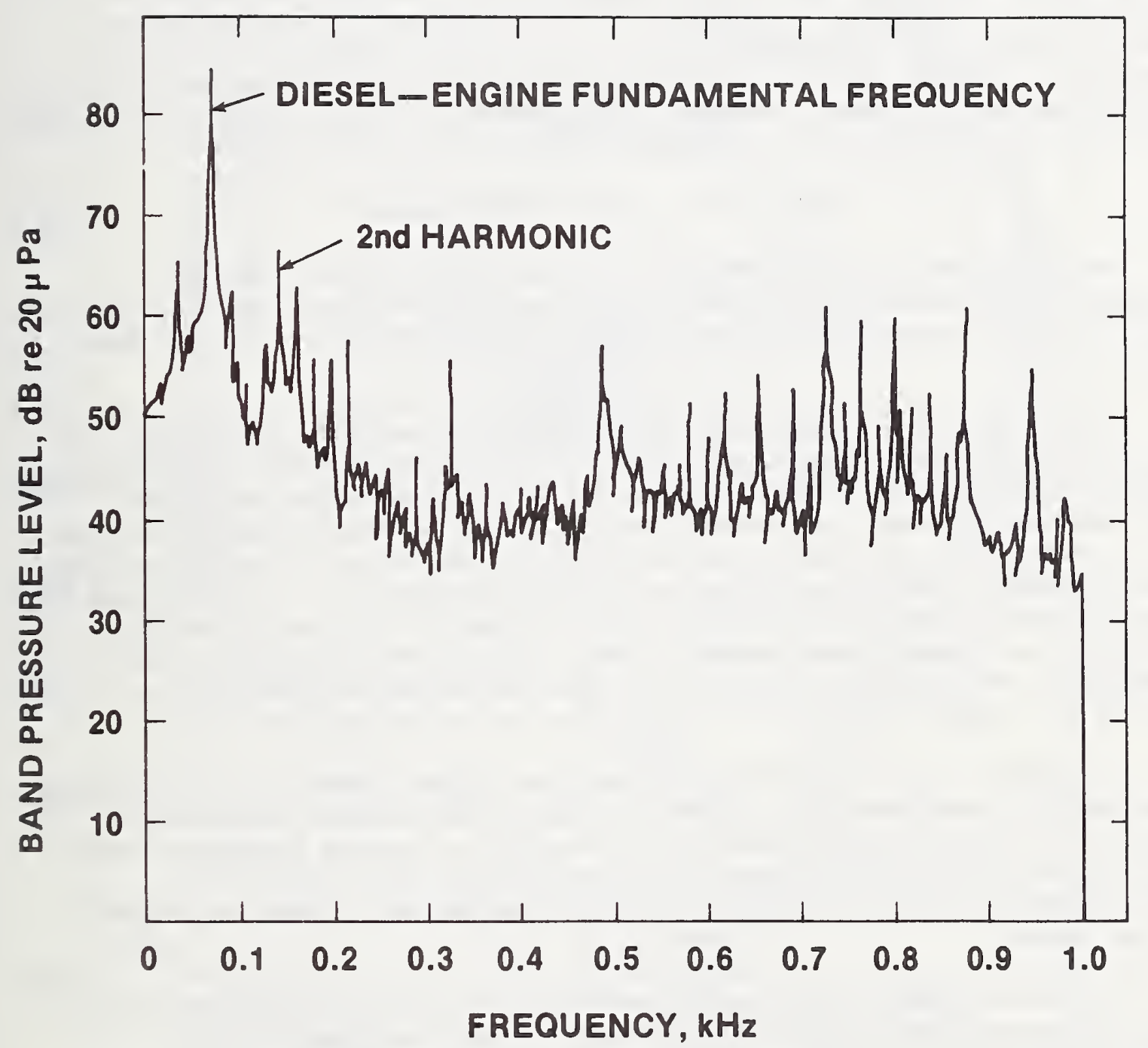

Figure 1. Refrigeration unit noise at maximum load at 50 feet $(15.2 \mathrm{~m})$ from truck mounted unit, directly in line with truck body[2]. (Bandwidth of the analysis used to obtain these data was not specified.) 
5.2. Choice of Appropriate Metric

5.2.1. Relationship of Appropriate Metric

to the Subjective Data Base

The physical characteristics of the radiated sound have been shown to include an unusually strong, discrete, low-frequency component and a cyclic time variation in the level and spectral characteristics. These considerations point to the possible inadequacy of simple measures such as A-weighted sound pressure level or equivalent sound level as reliable predictors of subjective response. Since the choice of an appropriate metric must be one that provides good correlation between the identified acceptable emission level and generally acceptable subjective reaction, it is imperative to obtain a relevant psychoacoustic and/or subjective data base upon which the choice of an appropriate metric can be based.

\subsubsection{Quantity to be Measured}

Measurements of sound pressure must be conducted in order to quantitatively characterize the noise emissions; however, the selected metric can be expressed in terms of either sound pressure level or sound power level.

The principal distinction between metrics based upon sound power or sound pressure level lies in the fact that sound power levels represent a spatially averaged or integrated measure of sound pressure emissions; whereas metrics based upon sound pressure levels are inherently sensitive to the details of the directionality of sound radiation. Therefore, when it is apparent that a source may be highly directional, it is important to clearly specify the directionality characteristics together with any (spatially averaged) sound pressure data. For moderately directional stationary sound sources, there is little preference between the two metrics in terms of ability to predict levels at remote locations.

There is some evidence to indicate that truck transport refrigeration units exhibit moderate directional radiation, although detailed data, characterizing an adequate sample of these units in many frequency bands, are not yet available. Figure 2 illustrates the nature of the directionality data for one unit for both A-weighted, linear and several octave bands.

It will be important, in the event that the chosen metric specifies sound pressure levels, that the associated measurement procedure appropriately identifies the presence of high sound pressure level lobes and that either appropriate spatial averaging or specification of measurement at the direction of maximum sound pressure levels be required. It is important to note, however, that sound power inherently accounts for the possible presence of source directionality since it is a measure of spatially integrated source emission. 


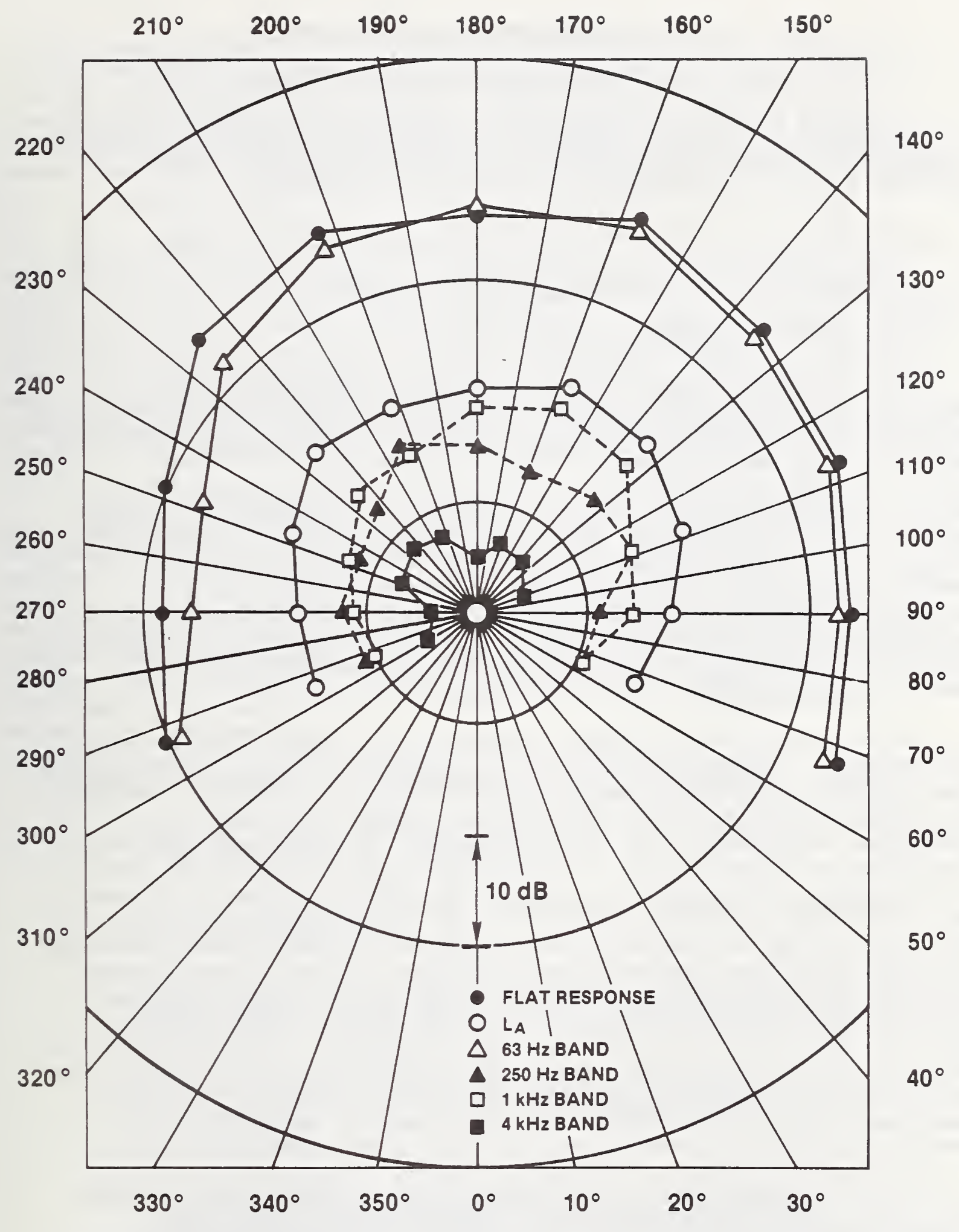

Figure 2. Directional radiation patterns for truck-mounted transport refrigeration units (A-weighted, flat response, and $63 \mathrm{~Hz}, 250$ $\mathrm{Hz}, 1 \mathrm{kHz}$, and $4 \mathrm{kHz}$ octave band data). Unit mounted on truck facing toward $180^{\circ}$; measurements taken at 50 feet $(15.2 \mathrm{~m})$ from unit. Note that the original data shows flat response $0.5 \mathrm{~dB}$ less than the sound pressure level in the $63 \mathrm{~Hz}$ octave band at $180^{\circ}[2]$. 


\subsubsection{Facilities and Measurement Procedures}

Facilities for the measurement of noise emissions from truck transport refrigeration units can be classified into three basic categories, differing in their environmental and acoustical properties:

(a) Outdoors, $\underline{\text { in }}$ situ, or free field over a reflection plane.

(b) Indoors, free field over a reflecting plane.

(c) Indoor, reverberation room.

Specification of one or more of these test facllities for the measurement is complicated by the existence of mutually exclusive or contradictory preferential factors. For example, thermal load control and control of external environmental factors are important to accurate specification of test conditions. These factors favor the use of one of the indoor test facilities. However, because of the presence of engine exhaust, indoor semi-anechoic facilities could potentially suffer wedge soiling with attendant acoustical performance degradation. Indoor reverberation room facilities also would experience wall soiling. Furthermore, special considerations are required in the design, operation, and maintenance of indoor facilities due to the presence of the exhaust fumes from many of these units. These considerations favor the use of outdoor test facilities.

Two physical factors indicate that indoor facilities, if selected, must be large. The presence of discrete frequency sources in reverberation rooms imposes special performance limitations upon the facility. Unusually large reverberation room facilities may be required to obtain truly reverberant conditions in the $40-100 \mathrm{~Hz}$ range. To some extent the source directionality characteristics as well as the absolute levels are affected by the presence of the truck or trailer body. These effects are due not only to the acoustic baffle effects provided by the large truck or trailer body, but also may include secondary radiation due to structural resonances excited by vibrations induced by unit operation. Unless it can be shown that directionality data are unimportant, that effects due to baffling by the truck body are predictable, and that, for typical units, secondary radiation from the truck or trailer body is negligible, the tests should be conducted with the units mounted on trucks or trailers. Indoor facilities large enough to accomodate such large units are not common. No unusual requirements exist for outdoor facilities, except in terms of characterization of the acoustical properties of the reflecting surface.

In the presence of discrete frequency sources, interference effects between the directly propagating sound energy and the sound energy reflected off the ground, test pad surface, or reflecting plane in general can lead to appreciable errors in the measurement of sound pressure levels. 
Careful characterization of the acoustical properties of the reflecting surface are essential, though difficult to specify and obtain for the typical out-of-doors ground surface. Qualification procedures for the acoustic environment such as those contained in several recent draft international and national standards[3-5] provide an important means to ensure that the measurement uncertainty due to reflecting plane effects will not be excessive.

Errors due to reflecting plane interference effects can be minimized by conducting measurements "close in" to the source (in the acoustic "near field") in order to estimate the acoustic power. In this case it may not be critical whether the surrounding environment is precisely specified and well controlled, which introduces a relaxation in the stringency of test site specification and may result in reduced facility cost. However, it has not been conclusively established at the present time that near field measurements allow an adequately accurate extrapolation of the data to yield the far field pressure levels, which are usually of principal interest.

Once an appropriate metric is selected and a facility has been specified, a decision must be reached as to whether or not the metric is to be expressed in terms of sound pressure level at a particular, well-specified location or set of locations or in terms of the sound power level. While it is realized that direct measurements of sound power emissions are not possible, estimation of power emission is possible using several measurement methodologies, and specification of sound power level enables ready estimation of levels at large distances, without the requirement for specification of directionality and/or source/receiver orientation information.

Several measurement procedures can be cited as potentially relevant.

-- American National Standard Methods for the Measurement of Sound Pre:ssure Levels, S1.13-1971[6].

-- American National Standard Method for the Physical Measurement of Sound, S1.2-1962[7].

-- Draft International Standard Acoustics - Determination of Sound Power Levels of Noise Sources - Engineering Methods for Free Field Conditions over a Reflecting Plane, ISO/DIS 3744[3].

-- American National Standard Methods for the Determination of Sound Power Levels of Small Sources in Reverberation Rooms, S1.21-1972[5].

Draft International Standard Acoustics - Determination of Sound Power Levels of Noise Sources - Precision Methods for Discrete-Frequency and Narrow Band Sources in Reverberation Rooms, ISO/DIS $3742[4]$. 
However, no one of these measurement procedures is specifically directed to this type of source. Thus, an adaptation of these measurement procedures to the specific chosen metric and facility, appropriate to the special constraints imposed by the nature of these sources, w1ll have to be performed prior to regulation of the noise emisston.

\subsubsection{Special Site and Environmental Consideratjons}

It is generally impossible to control all of the important environmental and site parameters affecting data at outdoor test sites. Therefore, correction factors are often desirable so that data can be "corrected" or converted to indicate the values which would have been obtained under a single, standard, set of test conditions. Parameters which are known to affect the generation and radiation of sound include atmospheric parameters (which affect the operation of internal combustion engines) and mechanical properties of the mounting surfaces (which may involve the vibration response of the truck or trailer body). A parameter important to the propagation of sound is the characteristics of the "reflective plane". In particular, if the surface is paved, it may degrade mechanically due to wear and weathering effects. If the surface is grass covered, the condition of the grass may vary considerably. In both cases, the acoustical properties may be essentially uncontrolled. A further environmental parameter which is difficult or impossible to control is the detailed nature of temperature and wind gradients above the reflecting plane. These gradients may vary appreciably throughout the course of a day or even during a brief series of tests.

The development of suitable correction factors to account for these environmental and site variables is an area where research is necessary. If the use of correction factors is not feasible, then there is need for a site calibfation procedure or a highly specific (and possibly severely restrictive) limiting set of test conditions.

Indoor test environments are not representative of the environment in which truck mounted refrigeration units are typically operated. Thus, if an indoor test site is selected, it is necessary to establish thc relationship between the characteristics observed in the indoor test environment and the "real world". In particular, it would be necessary to determine whether source directionality effects and possible secondary sources of radiation would be altered due to the absence of the truck body.

It is desirable to ensure that nolse emission data are obtained under conditions of maximum thermal loading. These conditions are typically obtained at temperatures on the order of $100^{\circ} \mathrm{F}\left(37.8^{\circ} \mathrm{C}\right)$, which are not frequently encountered in large portions of the United States. Thus if the chosen metric requires a measurement methodology predicated upon use of an outdoor test site, it wlll be essential to specify some alternative environmental loading condition. If, on the other hand, an indoor test methodology is selected, the facility must have the capability of 
supplying the required thermal load to the refrigeration unit in addition to handling the exhaust effluent from the engine.

\subsubsection{Provision of a Physical Data Base}

A physical data base is an essential element in the reduction of noise radiated by truck transport refrigeration units. This data base is essential for at least two reasons:

(a) An adequate data base is required for the identification of acceptable emission levels, using the appropriate metric and measurement methodology. The present data base is so limited that adequate accounting for such factors as unit-to-unit variability, details of mounting and operational characteristics, directionality, etc. -- all of which will be vital to effective implementation and enforcement of noise emission regulations -is not possible.

(b) Only a limited amount of data is available to the manufacturers for guidance in implementation of noise control programs. These data are to a large extent, proprietary, and are not available to many of the manufacturers. While the technology exists for a modest reduction of noise emissions, the cost effectiveness of existing noise control technology has not been adequately determined, and a substantial reduction of unit noise will require extensive redesigns in most cases.

Provision of an adequate physical data base should incorporate studies of the following factors:

(1) Noise versus load

(a) Engine noise alone

(b) Fan and compressor alone

(c) Total unit

(2) Unit directivity

(a) Octave band or one-third octave band; with trailer

(b) Octave band or one-third octave band; without trailer

(c) A-weighted and/or "linear"; with trailer

(d) A-weighted and/or "linear"; without trailer

(3) Sound power output

(a) With trailer

(b) Without trailer

(4) Correlation of indoor and outdoor tests 
(5) Study of environmental factors in outdoor tests

(6) Effects of mounting rigidity upon noise emission

(7) Measurement uncertainties associated with

(a) Outdoors

(b) Semi-anechoic

(c) Reverberant measurement environments

\subsection{Summary}

In summary, at the present time existing data bases -- both subjective and objective -- are not sufficient to allow EPA to (1) select a suitable physical metric that correlates with human response, establish an appropriate measurement procedure, and (3) perform a comprehensive analysis of the economic factors and technical feasibility associated with a given proposed regulation. Thus it appears that EPA must generate an extensive psychoacoustic data base as well as obtain an adequate physical data base prior to formulation of the Notice of Proposed Rule Making.

\section{References}

[1] The Williamsburg Conference on Noise Research, Vehicle Research Institute, Society of Automotive Engineers, Inc., New York, New York (1973).

[2] Diesel-powered Heavy-Duty Refrigeration Unit Noise, Donaldson Company, Inc., Minneapolis, Minnesota (1975).

[3] Draft International Standard Acoustics - Determination of Sound Power Levels of Noise Sources - Engineering Methods for Free Field Conditions over a Réflecting Plane, ISO/DIS.3744.

[4] Draft International Standard Acoustics - Determination of Sound Power Levels of Noise Sources - Precision Methods for Discrete-Frequency and Narrow Band Sources in Reverberation Rooms, ISO/DIS 3742.

[5] American National Standard Methods for the Determination of Sound Power Levels of Small Sources in Reverberation Rooms, S1.21-1972, American National Standards Institute, New York, New York (1972).

[6] American National Standard Methods for the Measurement of Sound Pressure Levels, S1.13-1971, American National Standards Institute, New York, New York (1971).

[7] American National Standard Method for the Physical Measurement of Sound, S1.2-1965, American National Standards Institute, New York, New York (1962). 
NBS-114A (REV.7-73)

\begin{tabular}{|c|c|c|c|}
\hline $\begin{array}{l}\text { U.S. DEPT. OF COMM. } \\
\text { BIBLIOGRAPHIC DATA } \\
\text { SHEET }\end{array}$ & $\begin{array}{l}\text { 1. PUBLICATION OR REPORT NO. } \\
\text { NBSIR } 75-964\end{array}$ & $\begin{array}{l}\text { 2. Gov't Accession } \\
\text { No. }\end{array}$ & 3. Recipient's Accession No. \\
\hline \multirow{2}{*}{\multicolumn{3}{|c|}{$\begin{array}{l}\text { 4. TITLE AND SUBTITLE } \\
\text { AN EVALUATION AND ASSESSMENT OF EXISTING DATA AND } \\
\text { PROCEDURES FOR THE MEASUREMENT OF NOISE FROM TRUCK } \\
\text { TRANSPORT REFRIGERATION UNITS }\end{array}$}} & $\begin{array}{l}\text { 5. Publication Date } \\
\text { December } 1975\end{array}$ \\
\hline & & & 6. Performing Organization Code \\
\hline \multicolumn{3}{|c|}{$\begin{array}{l}\text { 7. AUTHOR(S) } \\
\text { B. R. Fuller, W. A. Leasure, Jr., and D. S. Pallett }\end{array}$} & $\begin{array}{l}\text { 8. Performing Organ. Report No. } \\
\text { NBS IR 75-964 }\end{array}$ \\
\hline \multirow{2}{*}{\multicolumn{3}{|c|}{$\begin{array}{l}\text { 9. PERFORMING ORGANIZATION NAME AND ADDRESS } \\
\text { NATIONAL BUREAU OF STANDARDS } \\
\text { DEPARTMENT OF COMMERCE } \\
\text { WASHINGTON, D.C. } 20234\end{array}$}} & $\begin{array}{l}\text { 10. Project/Task/Work Unit No. } \\
2000451\end{array}$ \\
\hline & & & 11. Contract/Grant No. \\
\hline \multirow{2}{*}{\multicolumn{3}{|c|}{$\begin{array}{l}\text { 12. Sponsoring Otganization Name and Complete Address (Street, City, State, ZIP) } \\
\text { Office of Noise Abatement and Control } \\
\text { U. S. Environmental Protection Agency } \\
\text { Washington, D. C. } 20460\end{array}$}} & $\begin{array}{l}\text { 13. Type of Report \& Period } \\
\text { Covered } \\
\text { Final Report }\end{array}$ \\
\hline & & & 14. Sponsoring Agency Code \\
\hline
\end{tabular}

15. SUPPIEMENTARY NOTES

16. ABSTRACT (A 200-word or less factual summary of most significant information. If document includes a significant bibliography or literature survey, mention it here.)

This report reviews existing noise measurement procedures with regard to their usefulness in the regulation of truck transport refrigeration noise as well as the avallability, extent and applicability of existing data. On the basis of this review, probable or potential measurement difficulties are identified that could hinder the promulgation and/or enforcement of future EPA regulations to control the noise emission from truck transport refrigeration units.

17. KEY WORDS (six to twelve entries; alphabetical order; capitalize only the first letter of the first key word unless a proper name; separated by semicolons)

Acoustics (sound); measurement methodology; noise emission standard; noise measurement; refrigeration; truck transport refrigeration unit.
18. AVAILABILITY
$\Gamma$ - Unlimited

[X For Official Distribution. Do Not Release to NTIS

(O)rder From Sup. of Doc., U.S. Government Printing Office Washington, D.C. 20402 , SI) Cat. No. C13

Order lirom National Technical Information Service (NTIS) Springfield, Virginia 22151

\begin{tabular}{|l|c|}
\hline $\begin{array}{l}\text { 19. SECURITY CLASS } \\
\text { (THIS REPURT) }\end{array}$ & 21. NO. OF PAGES \\
UNCL ASSIFIED & 20 \\
\hline $\begin{array}{l}\text { 20. SECURITY CI.ASS } \\
\text { (TIIS PAGE) } \\
\text { UNCLASSIFIED) }\end{array}$ & 22. Price \\
\hline
\end{tabular}


